\title{
ANÁLISE TAXONÔMICA E BIOGEOGRÁFICA DE LEGUMINOSAE (FABACEAE) DO REFÚGIO DE VIDA SILVESTRE (REVIS) DO RIO DOS FRADES
}

\author{
AUTOR: JUAN FONSECA BAGGI \\ CO-AUTOR/ORIENTADOR: JORGE ANTONIO SILVA COSTA
}

Resumo: A perda de habitat é a principal causa da diminuição da biodiversidade no mundo e a Mata Atlântica é um exemplo extremo, onde um fragmento, mesmo muito pequeno e isolado, pode ser o único lugar propício para uma determinada espécie. O Refúgio de Vida Silvestre do Rio dos Frades (REVIS Rio dos Frades) é uma unidade de conservação federal criada por Decreto Presidencial S/No em 21 de dezembro de 2007 numa área de 894 hectares no município de Porto Seguro, Bahia. O levantamento florístico no REVIS Rio dos Frades vem sendo realizado desde o ano de 2018, em parceria com o ICMBio através de seus gestores. Para dar continuidade ao projeto, são propostos aqui pesquisas complementares para auxiliar no entendimento da composição da flora da Unidade de Conservação, através do estudo de famílias botânicas importantes quanto ao número de espécies, endemismos e distribuição geográfica a fim de se fazer uma análise de similaridade mais precisa com outros ambientes de restinga presentes na Bahia e no Brasil. Dessa forma, propõe-se estudar a taxonomia e a biogeografia da família Leguminosae para se ter um panorama da relação ambiental do REVIS do Rio dos Frades com os ambientes da Mata Atlântica, contribuindo ainda com o conhecimento da flora presente na Floresta Costeira da Bahia (FCB).

Palavras-chave: Leguminosae, Fabaceae, Análise Taxonômica, Rio do Frades. 